\title{
Retour sur « Du beau à l'identité »
}

\section{Catherine Hincker}

\section{OpenEdition}

\section{Journals}

Édition électronique

URL : https://journals.openedition.org/tc/5103

DOI : $10.4000 /$ tc. 5103

ISSN : 1952-420X

\section{Éditeur}

Éditions de l'EHESS

\section{Édition imprimée}

Date de publication : 30 juin 2010

Pagination : 610-612

ISSN : 0248-6016

\section{Référence électronique}

Catherine Hincker, « Retour sur « Du beau à l'identité » », Techniques \& Culture [En ligne], 54-55 | 2010, mis en ligne le 30 juin 2013, consulté le 29 septembre 2022. URL : http://journals.openedition.org/tc/ 5103 ; DOI : https://doi.org/10.4000/tc.5103 

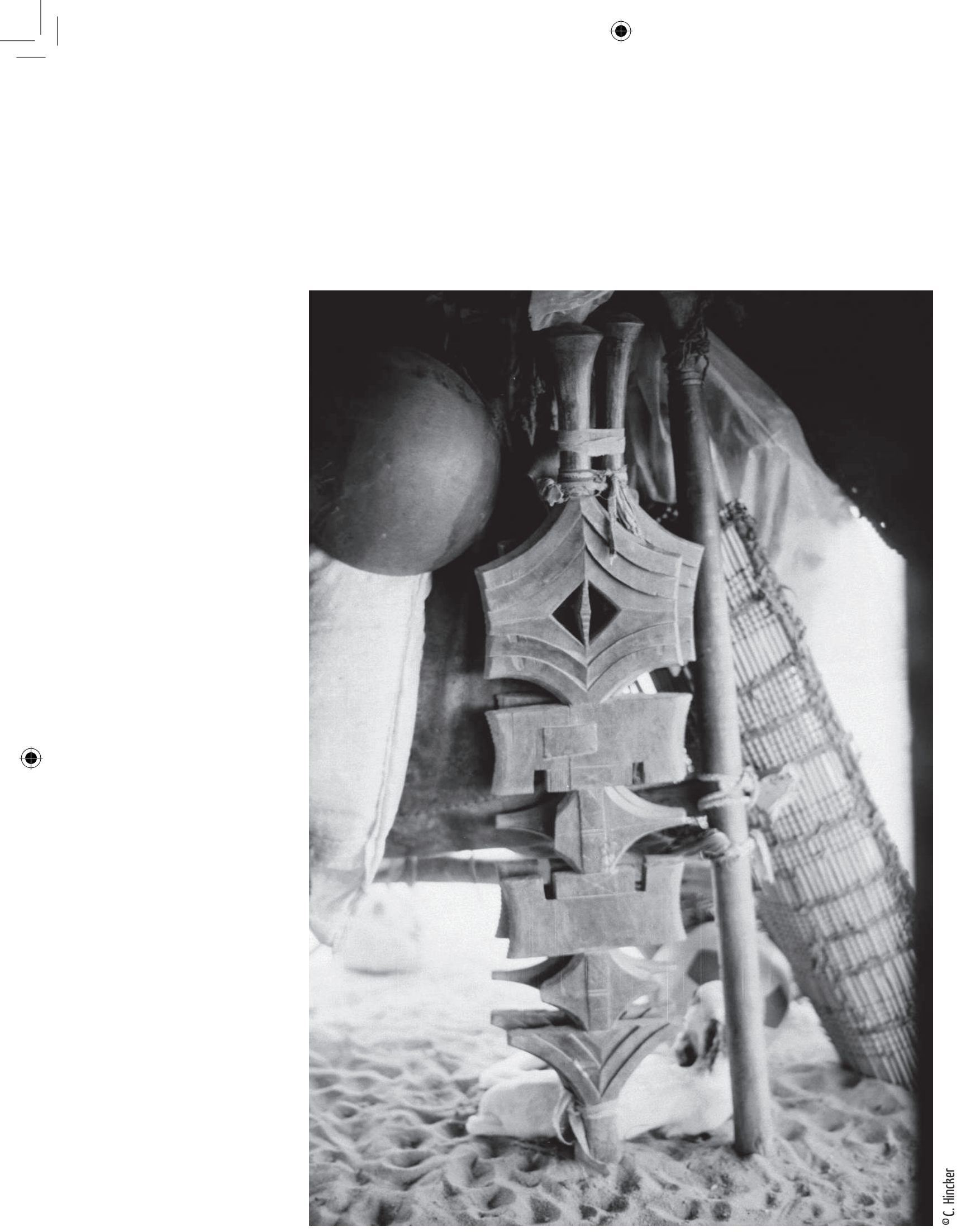

$\oplus$ 


\section{« Du beau à l'identité »}

Comme de nombreux textes, celui-ci publié en 2003 a été écrit quelques années auparavant. Il a donc une bonne dizaine d'années et s'inscrit dans le cadre d'une recherche menée sur les techniques en général, qu'il s'agisse de celles de fabrication, d'acquisition, de consommation ou de transport dans les sociétés sahariennes. Il est donc une étape ou un maillon d'une analyse globale dont l'une des ramifications m'a entraînée vers l'analyse du style et des conceptions esthétiques des Touaregs de l'Ouest.

Avec le recul, il me semble que l'un des apports de cet article réside dans la présentation minutieuse de la méthode ethnologique employée et de l'impact qu'elle peut avoir sur la construction d'une problématique et dans le traitement des données. Les guides d'enquête, les questionnements que nous élaborons avant le départ sur le terrain, s'ils ont leur utilité, doivent être ajustés pour correspondre avec pertinence à la réalité observée. Quel intérêt aurait l'ethnologie si nous savions dès le départ comment fonctionne la société avec laquelle nous envisageons de travailler? Le défi que le chercheur doit relever est d'arriver à saisir des modes d'appréhension de la réalité radicalement différents des siens. En somme, la réalité ethnologique dépasse de très loin la fiction (dans le sens de «création de l'imagination »). Toute la difficulté est d'arriver à concevoir qu'est-ce qui préoccupe nos interlocuteurs, pourquoi tel sujet est plus porteur qu'un autre dans la société considérée.

Le recours à l'immersion, l'apprentissage, indispensable à mon sens, de la langue vernaculaire, le partage des moments du quotidien permettent d'établir une distance optimale où le sujet prend tout son sens. Pour illustrer ce point de vue, je ferai appel à la métaphore de la vision. Lorsque l'on regarde un objet très éloigné, on ne le voit que globalement, sans en saisir les spécificités. De même, lorsque l'on regarde un objet de trop prêt, on n'en voit qu'une partie. Il me semble possible de trouver une 
distance confortable où l'on peut appréhender la réalité qui nous entoure dans toute sa singularité sans tomber dans des généralisations abusives ni dans l'exposé de cas trop particuliers.

Ces postulats méthodologiques posés, j'ai utilisé un mode classique de collectes de données en tenant un journal (sans trop d'assiduité, je l'avoue!), en réalisant des entretiens enregistrés et traduits littéralement, puis en analysant et indexant les informations recueillies. Cette méthode, centrée sur le langage et l'observation, parfois contraignante et laborieuse a le grand mérite de la précision, de l'exactitude. Elle permet une analyse en profondeur des sujets et a le mérite d'être un reflet d'une réalité. 